\title{
Effect of aspirin on pruritus
}

\author{
B MARTINA DALY， SAM SHUSTER
}

\begin{abstract}
The effect of $900 \mathrm{mg}$ aspirin on persistent itch from chronic dermatoses other than urticaria (eight patients) and other causes (five patients) was measured subjectively using a $10 \mathrm{~cm}$ line and objectively as nocturnal scratch using limb meters. There was no change in itch or scratch and it is concluded that aspirin neither affects itch centrally by a pain related mechanism nor affects itch physiologically by cyclo-oxygenase inhibition in the skin.
\end{abstract}

\section{Introduction}

Because of the relation of itch and pain ${ }^{12}$ and the ability of certain prostaglandins to lower the itch threshold when applied topically ${ }^{3+}$ we studied the effect of aspirin on pruritus due to skin disorders and other causes. Itch was assessed subjectively using a $10 \mathrm{~cm}$ analogue scale and objectively using limb meters which measure nocturnal scratch.

\section{Patients, methods, and results}

We studied 13 patients (six male) aged 14-65 (mean $33 \cdot 2$ years). Six patients had atopic or chronic discoid eczema, two psoriasis, two primary biliary cirrhosis, and three pruritus of unknown aetiology. All oral medication was stopped two davs before the study and aqueous cream was the only topical preparation used. No patient had a recent or past history of peptic ulceration. The study was open: no treatment was given on nights one and two, aspirin $(900 \mathrm{mg}$ ) was given at 2200 on the third and fourth nights, and no treatment was given on nights five and six. On each of the six consecutive nights itch was measured objectively as nocturnal scratch using limb movement meters' applied from 2300 to 0600 and assessed subjectively by the patients marking a $10 \mathrm{~cm}$ analogue scale each morning. Mean figures were calculated for each two day study period.

There was interindividual and intraindividual variation in itch and scratch

\footnotetext{
Department of Dermatology, Royal Victoria Infirmary, Newcastle upon Tyne NE1 4LP

B MARTINA DALY, MB, MRCPI, senior registrar

SAM SHUSTER, PHD, FRCP, professor and head of department

Correspondence to: Professor Shuster.
}

Effect of $900 \mathrm{mg}$ oral aspirin on nocturnal itch and scratch expressed as mean (SEM) of data for all 13 patients

\begin{tabular}{lccc}
\hline & $\begin{array}{c}\text { Before } \\
\text { treatment }\end{array}$ & $\begin{array}{c}\text { During } \\
\text { treatment }\end{array}$ & $\begin{array}{c}\text { After } \\
\text { treatment }\end{array}$ \\
\hline Visual analogue scale & $3 \cdot 5(0 \cdot 5)$ & $\begin{array}{c}\text { Itch } \\
3 \cdot 3(0 \cdot 4)\end{array}$ & $3 \cdot 1(0 \cdot 5)$ \\
Units of nocturnal limb movement & $46 \cdot 3(10 \cdot 0)$ & $\begin{array}{c}\text { Scratch } \\
38 \cdot 8(7 \cdot 4)\end{array}$ & $38 \cdot 7(5 \cdot 5)$ \\
\hline
\end{tabular}

throughout the study, but no consistent change in either measurement was recorded during aspirin treatment (table). No adverse effects were noted and there was no change in the underlying disorder during the period of study.

\section{Comment}

We found no effect of oral aspirin on itch due to skin or other diseases, though the method used to measure itch as scratch is objective and reliable 5 and the dose of aspirin was enough for an analgesic effect. We can therefore exclude the possibility that therapeutic doses of aspirin have a central effect on pruritus. It has also been suggested that the itch of disorders such as eczema might be due to a lowering of the itch threshold by prostaglandins such as $\mathrm{PGE}_{2}$ produced by the disordered skin ${ }^{3}$; this effect is only slight, however, and its relevance is uncertain since various stimuli alter the itch threshold.' Though we do know what oral dose of aspirin is required to inhibit cyclo-oxygenase activity in skin, the lack of effect of aspirin in our study gives no support to the view that prostaglandins play a part in the itch of inflammatory dermatoses such as eczema.

\section{References}

1 Keele CA, Armstrong D. Substances producing pain and itch. Monogr Physiol Soc $1964 ;$ Nol2

2 Sinclair D. Cutaneous sensation. London: Oxford University Press, 1967:144-6

3 Greaves MW, McDonald-Gibson W. Itch; role of prostaglandins. Br Med $\mathcal{F} 1973$;iii: 608-9.

4 Lovell CR, Burton PA, Duncan EHL, Burton JL. Prostaglandins and pruritus. $B r \mathcal{F}$ Dermatol 1976;94:273-5

5 Felix RH, Shuster S. A new method for the measurement of itch and the response to treatment. Br F Dermatol 1975;93:303-12.

(Accepted 14 August 1986) 